\title{
La BloGoteca de Babel
}

2011

Introducción

Pedro Porbén

Bowling Green State University

Follow this and additional works at: https://scholarworks.bgsu.edu/blogotecababel

Part of the Caribbean Languages and Societies Commons, and the Spanish and Portuguese Language and Literature Commons

How does access to this work benefit you? Let us know!

\section{Recommended Citation}

Porbén, Pedro (2011) "Introducción," La BloGoteca de Babel: Número 2 , Article 6.

DOI: https://doi.org/10.25035/blogotecababel.02.01.06

Available at: https://scholarworks.bgsu.edu/blogotecababel/vol2/iss1/6

This Dossier is brought to you for free and open access by the Journals at ScholarWorks@BGSU. It has been accepted for inclusion in La BloGoteca de Babel by an authorized editor of ScholarWorks@BGSU. 


\section{Introducción}

Pedro P. Porbén

Los cuatro ensayos recogidos en este dossier sobre el cómic latinoamericano como respuesta a Disney tienen como común denominador el cuestionamiento de las políticas de género y sexualidad implementadas por los creadores de cómics latinoamericanos como respuesta a las estereotípicas representaciones que de América Latina y el Caribe hicieron los productos culturales de Disney. Estos ensayos han sido el resultado de mi seminario de pre-grado ofrecido recientemente en BGSU. El tema, monumentalmente imposible de cubrir en un semestre, fue la cultura popular de América Latina y el Caribe con énfasis en las intersecciones de cuestiones de raza, género, sexualidad y clase social en el arte secuencial, el cine de animación y en particular en el cómic de varios países hispanohablantes. A lo largo del curso, los estudiantes fueron expuestos, por primara vez, a productos culturales creados fuera del monopolio Disney con cuyas producciones los estudiantes estaban sumamente familiarizados. Es decir, por primera vez, mis estudiantes discutieron críticamente en clases a nivel universitario cómics como Mafalda, Supertiñosa, Memín Pinguin, Cuy y Condorito, entre otros. Para muchos de ellos, Disney “clásico", representado por el Pato Donald, Mickey y Minnie Mouse, el perro Pluto, etc., había monopolizado no solamente la experiencia vivencial de sus generaciones sino que había 'castrado', simbólicamente, las estructuras socio-culturales en las que ellos y ellas se veían imbuidos ahora como consumidores de un producto estéril, "idealizado" y sobre todo alejado de "la realidad" de sus vidas cotidianas. Por otro lado, los cómics latinoamericanos y caribeños les parecieron al principio "fuertes" representaciones de una sexualidad "liberal" con la cual no concordaban los preceptos de ese Disney "clásico" con los cuales estaban mucho más familiarizados. Después de varias semanas realizando lecturas críticas de textos secundarios de autores como Michel Foucault, Antonio Gramsci, Jaques Derrida, Gilles Deleuze, David William Foster, Ana Merino, William Rowe y Vivian Shelling, sus perspectivas en cuestiones representacionales de clase social, género y sexualidad generaron los ensayos que hoy ponemos para su consideración. Les dejamos entonces con estos trabajos que comenzaron cuestionándose las representaciones que de América Latina y el Caribe habían hecho los cómics 
clásicos de Disney en las décadas de 1940 a 1960, y concluyeron subrayando las complejas imbricaciones entre género y sexualidad con clase social y raza en los cómics analizados. 